\title{
IMPLEMENTATION OF PRESSURE AND LEAKAGE MANAGEMENT STRATEGIES ON THE GOLD COAST, AUSTRALIA: A CASE STUDY
}

\author{
Mark Girard ${ }^{1}$ and Rodney A. Stewart ${ }^{2}$ \\ ${ }^{1}$ Executive Officer, Queensland Water Directorate, Brisbane, Queensland, Australia \\ ${ }^{2}$ Lecturer, School of Engineering, Griffith University, Gold Coast, Queensland, Australia
}

\begin{abstract}
\end{abstract}
Many water authorities, both nationally and internationally, have been forced to rethink their strategies for achieving water balance as a result of growing water demands, droughts, reduced no-failure yields and environmental sustainability considerations. In particular, regulatory bodies in Australia are demanding that water managers exhaust network management efficiencies before considering new water source options (e.g. dams, desalination, pipelines etc.). Demand management incentive schemes in conjunction with water recycling and pressure and leakage management (PLM) initiatives are a few examples of least-cost planning strategies being adopted by water authorities to achieve water balance without expanding the water infrastructure asset requirements. Potential benefits of PLM strategies have been predicted by these authorities worldwide, in areas such as: deferred capital works; reduced corrective maintenance; reduced treatment costs; energy savings; reduced reclaimed water discharges; and improvements to customer service. However, justification for PLM options remains difficult due to the limited amount of quantified evidence for most of the above-mentioned benefits over an urban water systems life cycle. As the first stage in the development of a holistic PLM decision support system this paper quantifies the benefits derived from a PLM strategy in a trial area located on the Gold Coast, in Queensland, Australia. The results of the trial provide evidence to support claims that PLM can reduce water consumption and the frequency of infrastructure failures if implemented throughout the entire Gold Coast City. Further to this, the research concludes that PLM impacts on the total water cycle and has broad implications for ensuring the future sustainability of potable water services. 
Keywords: pressure and leakage management, urban water systems, sustainability.

\section{Introduction}

While fresh water may be characterized as a renewable resource, it must always be remembered that once its' capacity has been absorbed, renewal in its simplest form as rainfall is neither predictable nor consistent. This fact was catalysed by the recent drought period that has touched most of the Australian continent during 2001-2004. Recent trends are suggesting amplification in the rate of climate changes. It is becoming evident that average annual rainfall in the eastern parts of the state of Queensland has fallen dramatically, particularly around the central parts. Predictive models of future average annual rainfall in Queensland suggest a 15\% reduction in rainfall by the year 2030 and $40 \%$ by 2070 (Crimp, 2004). As the second driest continent on the planet, Australia can least afford the proposed localized impacts of climate change. After almost four years of continued lower-thanaverage rainfall and with many water supply reservoirs at the lowest recorded levels, many Australian cities and towns continue to face severe droughts. The management of water resources is increasingly becoming a major concern for residential consumers, industry and all levels of government. Many of the water issues we face today result from the legacy of poor water resource management of the past, a rapidly changing climate due to global warming and changing attitudes to water use and security of supply. Australia is facing a water crisis in both the short and medium terms. In the short term, every Australian water service provider will need to adapt to the changing climatic conditions that are already impacting on the available yields of water storages across the country. This will include adopting new approaches to water management to meet the short-term water supply deficiencies. Over the medium to longer term, the Australian population will continue to grow from its' current 20 million people in 2004 (ABS, 2004) to reach its' predicted population peak of approximately 30 million people in the year 2050. All levels of Government in Australia must accept that the greatest challenge we may face is how we meet the water needs of future generations of Australians by investing in adequate planning now, to ensure a sustainable water future. 
In an attempt to better utilise existing urban water resources, this paper examines the benefits of PLM strategies, which is one of the least cost alternatives to meeting water supply needs. PLM was applied on a trial basis on the Gold Coast to measure its impact on the performance and consumption sustainability, asset management and total urban water life cycle. The main objectives of the investigation included: (1) investigating whether PLM is a valid demand management alternative for the Gold Coast; (2) evaluating the impact of PLM initiatives on water consumption and infrastructure failures on the Gold Coast; and (3) examining the feasibility of implementing PLM throughout the entire Gold Coast City. The outcomes of this investigation included: justification for the city-wide implementation of PLM on the Gold Coast; expansion of the water industry's knowledge of the impacts and benefits of PLM strategies; and the quantification of asset management benefits achievable from PLM implementation.

\section{Environment Context: Gold Coast City, Queensland, Australia}

The city of the Gold Coast is located approximately $80 \mathrm{~km}$ south of Brisbane in Queensland, Australia. Brisbane is the second largest municipality in Australia. The city of the Gold Coast is the second largest municipality in Queensland. The Gold Coast covers a land area of approximately 1.5 million hectares however the bulk of the population is concentrated along the eastern boundary of the city. The base population of the Gold Coast is approximately 500,000 people and swells three-fold during the peak summer holiday season in December and January (Gold Coast Water, 2004). The city of the Gold Coast is under half its' estimated permanent maximum population of 1.5 million people. It is estimated that this maximum population will be reached in the year 2055 (Gold Coast Water, 2004). Of great concern is how the city will cope with the holiday period peaks under the maximum population scenario, particularly the demand on water and roads infrastructure. The basic services (water, waste, roads, parks etc) of the city of the Gold Coast are managed by Gold Coast City Council (GCCC), an un-politicised Local Government Council. In many other states and territories in 
Australia, the provision of these services is a responsibility of the state government or these services are outsourced to the private sector.

\subsection{Gold Coast Water}

The provision of water supply and sewerage services fall under the auspices of a business unit of GCCC, Gold Coast Water (GCW). GCW is responsible for managing all aspects of water and sewerage and employs approximately 250 full-time personnel. GCW has an annual operating budget of approximately AUD\$20 million/annum and a recurrent capital works budget of approximately AUD\$30 million/annum. In the 2004/2005 financial year the water reticulation network was allocated approximately AUD\$8 million in capital works funding. Approximately half this amount (AUD\$4 million) was used in water main and water service renewals to maintain the level of service specified by GCW's Customer Service Standards (CSS). The operation and maintenance of GCW's water reticulation network costs in the order of AUD\$5 million/annum.

\subsection{Threatened Water Supply}

The Gold Coast has been under the influence of an extended drought period since late 2001. In January 2003, the Hinze Dam fell to its lowest level (28\%) since its construction in the early 1980's. The low dam level was the result of the lowest rainfall period ever recorded. The flows from the upper Nerang River into the storage ceased in July 2002. Average daily consumption in January 2002 was approximately $300 \mathrm{ML} /$ day and reduced to approximately $180 \mathrm{ML} /$ day under the various stages of restrictions. Studies have shown that approximately $50 \%$ of the daily demand is used in garden watering. This is evidenced by consumption data during and immediately following rainfall periods where demand decreases to approximately 100 ML/day (Gold Coast Water, 2003). 


\subsection{Gold Coast 'Waterfuture'}

Gold Coast Waterfuture is a branded product of Gold Coast Water. The aim of the Waterfuture project is to identify the city's future water sources and adequately plan the delivery of infrastructure to meet the water demands by the year 2055. On the basis of the city growing to a population of approximately 1.5 million people, the corresponding water demand will require approximately $465 \mathrm{ML} / \mathrm{day}$. The yield of the Hinze Dam has been downgraded following the worst drought on record and can now only sustain $175 \mathrm{ML} /$ day from its previous calculated safe yield of almost $400 \mathrm{ML} /$ day. The northern half of the Gold Coast water supply is currently supplemented with water from Brisbane’s Wivenhoe Dam at a rate of $30 \mathrm{ML} / \mathrm{day}$. The proposed Wivenhoe pipeline is capable of supplying $120 \mathrm{ML} / \mathrm{day}$. The supply shortfall over the next 50 years, however, is currently estimated at $170 \mathrm{ML} / \mathrm{day}$. This raises questions regarding the available sustainable yield from other potential water sources including recycled water, rainwater tanks, demand management incentive schemes, desalination and PLM. This paper will focus on how PLM can contribute towards achieving the city's 50 year water balance.

\section{Pressure and Leakage Management}

A catchphrase of academic research in the 1990's was the philosophy of intergenerational equity and sustainability in resource management. In Australia, these philosophies were adopted in the Federal government's environmental policy and were consequently adopted by the relevant State and Territory governments as basic principles in analysing both public and private infrastructure projects. While these policies are generally acknowledged and accepted in the government and private arena, integrating these philosophies into the decision making framework and processes remains less successful and transparent. Coupled with the failure to choose the most sustainable solution, attitudes to the security of our water supplies are changing and the public are demanding 'bullet proof' systems. In Queensland, past incumbent governments indulged in a spree of dam building across the state in the hope that rain would fall into the catchments and provide a secure water supply for the many rural and residential communities of Queensland. The approach at the time was as much a political decision as it 
was backed by the necessary science to justify the project. As the science of dam building and yield calculations come under increased scrutiny by regulatory authorities, governments can no longer approve new storages as the solution to water shortages and instead should focus their attention to analyse the least cost approaches to water supply solutions. Demand management initiatives, specifically PLM, is recognised as an effective, low cost, demand side solution. The following sections provide some persuasion as to why PLM is part of the solution to sustainable urban water systems.

\subsection{Least Cost Planning Approach}

Demand management is the alternative to supply side management, which is largely influenced by new water sources such as dams, desalination etc. The available elements of demand management include: water restrictions; advertising education campaigns; plumbing fixture retrofit programs and rebate schemes; pressure control; and leakage detection. In a comparative study of demand management options completed by Gold Coast Water (2003), PLM was determined to be the least cost alternative on a basis of \$/ML/day. Haddad and Lindner (2001) supports the results of local studies and critically analyses the prospect of effective demand management as an alternative to nonconventional water supply options in the Middle East. Their study confirms that the amount of water that needs to be mobilised will to a large extent be determined by future water policies and how they rely on demand management, wastewater reuse and bilateral resource agreements.

Further research is needed to identify and discuss the full range of demand management options available and how they compare with traditional and non-conventional water supply options. Further, the discussion should include an analysis of the triple bottom line aspects of each option. In may ways the approach of academics and water managers always turn to infrastructure solutions and these are largely driven by politics and the need for 'ribbon-cutting' and 'concrete solutions'. As Rockstrom (2003) discussed, the real solution lies in the way the resource is used, influencing consumption habits and agricultural use. As one of the least cost solutions, politicians and managers cannot ignore options such as PLM with an increasingly informed public demand transparency in decision making. 


\subsection{Benefits}

It has been known for some time in the water industry that the implementation of pressure management reduces the water losses occurring within the pipe systems of a water supply business (Cullen, 2004). For over 20 years, the Japanese have recognised that leakage varies with pressure in accordance with the 1.15 rule (i.e. a $1 \%$ increase in pressure results in a $1.15 \%$ increase in the leakage rate).

There are four leakage management activities that will constrain real losses, including, pipe materials management, speed and quality of repair, active leakage control and pressure management. Various software packages (FAVAD, BABE) have since been developed under the auspices of the International Water Association (IWA) to interpret the change in pressure and its effect on losses in a water distribution system. These have been successfully applied in various countries since 1994 to predict the effect of pressure management on leakage rates, consumption and income. Moreover, numerous international studies have concluded that high pressures can result in higher main burst frequencies (Thornton 2002; Carpenter et al., 2002; Jankovic-Nisic et al., 2004). Additionally, the decision to apply PLM should also reduce consumption and the energy consumption of the urban water system (deMonsabert et al., 1998; Colombo and Karney, 2005).

In summary, a wider international interest in PLM is essential to realise its benefits: achieves minimum standards of service; reduces new leaks; reduces excess pressure; reduces some components of consumption; and extends infrastructure working life.

\subsection{Benchmarking Water Losses}

Dan and Beaton (2004), explain that while expressing unaccounted for water or system losses as a percentage may be the simplest to communicate or understand, it is in fact misleading. The current 
best practice for measuring water losses is to express the losses as litres per connection per day. The Water Services Association of Australia (WSAA) has recently adopted a software tool to assist its members to measure losses in L/connection/day. This is consistent with the methodology of the International Water Association (IWA) on system water losses. The IWA carried out workshops with WSAA to define the water balance terminology and inputs that would be used to calculate leakage via 'benchloss'. Carpenter et al. (2002) explained that 10 of the 17 WSAA members used benchloss to calculate unavoidable annual real losses. The results of the calculations showed that Australia has a lower average density of connections per $\mathrm{km}$ and higher average pressures when compared to international data.

The best practice results are measured as basic PI's (litres/connection/day), Intermediate PI's (litres/service connection/day/meter of pressure), and detailed PI’s (infrastructure leakage index (ILI)). Current Annual Real Losses (CARL) includes the total volume of losses in a system. The Unavoidable Annual Real Losses (UARL) is the lowest technically achievable annual volume of real losses that a system can maintain. The ratio of the CARL to UARL is the ILI (Carpenter et al., 2002; Thornton, 2002; Cullen, 2004). ILI is non dimensional and is recognised by the IWA, WSAA and Ofwat as the best method to represent system performance relative to system losses. An ILI close to 1.0 represents a high standard of operational management. As ILI increases the quality of the operations management decreases. PLM is the key operational technique used and recommended to improve the ILI.

\subsection{Implementation}

The recognition that the effective management of pressure is the essential foundation of effective leakage management is not universally accepted. Five out of 20 countries do not use proactive pressure management. Many practitioners still believe that the effect of pressure management on leakage cannot be accurately predicted. Thornton (2002) suggests that inappropriate equipment has been the cause of problems where pressure management has been implemented. Their study provides 
an extensive toolkit to practitioners wishing to implement PLM strategies. Each of the recommendations of this study are summarised below.

Tasks to be undertaken prior to deciding whether to implement pressure management:

- Desktop study to identify potential zones, installation points and issues;

- Demand analysis to identify consumer types, control limitations and issues;

- Field measurements of flow and pressure at zone inlets, critical nodes and average zone points;

- Modelling the potential benefits (using FAVAD and BABE);

- Locating the correct control valves and control devices;

- Modelling the correct control regime to achieve the desired result; and

- Completing a cost benefit analysis.

The most common methods of pressure management include:

- Establishing zone boundaries;

- $\quad$ Pump and level control;

- Fixed outlet pressure control valves;

- Time modulated control valves;

- Flow modulated control valves; and

- Remote node control.

Recommended further research required to better understand the impact of pressure management on:

- Changes in consumption and revenue;

- Minimum fire fighting capacity and automatic sprinkler system requirements;

- Irrigation system capacity;

- More dead-ends and water quality problems; and

- Hydraulic capacity and storage fill cycles. 
In summary, Thornton (2002) suggests all methods of pressure management should be considered in the economic analysis in order to identify the most effective and efficient method of reducing pressure and leakage in the water distribution system.

\subsection{Leak Detection}

Leak detection is an important activity in minimising water losses (Thornton, 2002). In most water distribution systems a large percentage of water, typically $20-30 \%$ but up to $50 \%$ for older systems, is lost in transit from treatment plants to consumers. Hunaidi (2000) suggested systematic leakage control involves two key components, namely, audits and leak detection surveys. Auditing is expensive as it must be carried out during the night when demand is low and 'noise' doesn't interrupt leakage detection equipment. Recent trends include setting up permanent zone metering and telemetry to trend flow and pressure data to a SCADA system to monitor any changes in minimum night flows. Critical points can then be set to trigger a leakage detection survey. Leak detection surveys are conducted following or in parallel with a water loss audit. Acoustic devices are typically used to pinpoint the location of a leak. These devices detect sound or vibration from water escaping a pressurised pipe. The sound and vibration are transmitted along the pipe and in the soil adjacent to the leak. More recently, researchers are attempting to reduce the level of field observations required through better leak detection methods (Buchberger and Nadimpalli, 2004; Misiunus et al., 2005).

\subsection{Role of Data Management and Network Modelling}

Babovic et al (2002) demonstrated the high volume of waste occurring as a result of poorly managed water reticulation assets. They recognised that water main breaks are rising to unsustainably high levels in many parts of the world and the need to manage them is becoming a priority for many water managers. They proposed that the asset management databases kept by water authorities need to be used more effectively and demonstrated that the asset management database can be used as a risk 
assessment model and consequently used to optimise rehabilitation programs to repair water mains before they break. Finally, they recommended further research to replicate this approach on other network models to observe the results and confirm the direction for water authorities, that is to invest in a data driven approach (score based + genetic algorithms) or the combined data and knowledge approach (Bayesian model).

The role of network modelling in modern water reticulation systems is critical to meet the minimum standards of service required to meet demand and fire flows. While PLM is in its gestational phase in Australia, throughout Europe and the United States, network modellers have been researching ways to optimise the performance of the network following the pressure management framework. The research of Burrows et al. (2000) and Poulakis et al. (2003) examined the operational and maintenance aspects of the reticulation system that could benefit from network modelling applications. Other researchers are developing GIS-supported spatial decision support systems (SDSS) to assist urban water planners to formulate optimized strategies which incorporate social, economic and engineering constraints (Makropoulos et al., 2003).

\subsection{Social Impacts}

The preference for supply-side engineering solutions to water supply limitations has perpetuated the slow uptake of water demand management as an effective conservation measure and management technique. Kolokytha et al. (2002) investigated the attitudes and preferences of the residential water users of the City of Thessaloniki in Greece in order to evaluate the demand management aspects of the urban water policy. Their study concluded that people prefer supply side engineering solutions to water supply problems and don't trust many demand management solutions. Their research reveals that changing consumer attitudes will play an important role in future water supply planning. Dube and Zaag (2003) undertook consequent research to examine the choices for modern urban water services providers to determine whether to continue to build new infrastructure or opt for demand management. They analysed the water use patterns of the water customers in the city of Masvingo, 
Zimbabwe to determine whether the city was capable of influencing demand by introducing: a new tariff structure; PLM; and awareness campaigns. Their study established that by introducing PLM they estimated they could reduce the daily water balance by $7 \%$. They concluded that a combination of successfully implemented demand management measures is required to defer capital investment in supply side infrastructure solutions

\subsection{Policy and Legislative Instruments}

Only in the last few years has the importance of regulating the water industry become a priority. Overuse in combination with extended drought periods is possibly the driver for policy reform in Africa and many other parts of the world (Dube and Zaag, 2003). In line with the outcomes of the research by Dube and Zaag (2003), the declining availability of water resources in Malawi, South Africa, led to their government introducing water demand management as an initiative to minimise waste and maximise the community’s approach to the value of water (Mulwafu et al., 2003).

In Southern Africa, Mwendera et al. (2003) suggests there are a distinct lack of policy and legislative instruments to support water demand management and recommends that the following basic strategies should be developed: controlling system water losses and other UAW (metering, theft etc); introducing equitable water charges; and preventing pollution, unnecessary stream flow reduction and water source exploitation. Sokile et al. (2003) explored the institutional framework in Tanzania focusing on the problems of misuse and mismanagement under the existing system. They argued for greater integration of water management and that appropriate institutional frameworks are necessary to lift the constraints imposed on water user associations in fostering and enhancing the sustainability of water management. Developing a better understanding of the linkages between stakeholders and intersectoral water managers is a challenge for water service providers across the world (Dube and Zaag, 2003; Mulwafu et al., 2003; Mwendera et al., 2003; Sokile et al., 2003). 


\subsection{International Context}

Severe drought in New Zealand in 1994/1995 prompted a water cycle strategy that promoted sustainable water management solutions at a local level. Pressures were reduced as an emergency measure during the water shortage. Following the drought, it was decided to reduce the system pressures on a permanent basis. The chronic rate of failure of water mains was another reason for the pressure management project. Pilipovic and Taylor (2002) present a case study covering the design and implementation of the pressure standardisation program carried out in Waitakare City and its results. A pilot zone was used to determine the potential for leakage reduction in the city. The pilot area comprised 1250 connections. Pressure was reduced to between 200-500 kPa. The pressure reduction exercise was carried out over a number of stepped reductions. This approach resulted in only five (5) complaints being registered. The observations of the performance of the water network following the reduction in pressure included: $10 \%$ reduction in water consumption; $5 \%$ reduction in wastewater entering the WWTP’s (saving approximately NZ\$0.5M/annum); less water main breaks; reduction in water losses worth approximately NZ\$300k/annum; and asset life increased by approximately 10-20 years

In Portugal, Marques and Monteiro (2002) report that the national average for unaccounted for water was estimated at $35 \%$. The larger cities initiated some form of leakage management to minimise system losses. These include metering, pressure management, district metering, leak detection, mains renewals and meter replacement, and maintenance enhancement. The availability of European Union funding has initiated some of the performance optimisation projects. Funding policy relies on improvements to customer service and reductions in operations and maintenance costs. The conclusions of their study on the state of water losses in Portugal include: (1) the poor performance of the Portuguese water industry is a result of investment in new assets and a lack of attention to the operation of the existing system; and (2) further research is required to measure the performance of water businesses following the implementation of demand management initiatives. 


\subsection{Gold Coast Context}

In $2002 / 2003$, approximately $10 \%$ of the potable water supplied to the Gold Coast City from the Molendinar and Mudgeeraba Water Purification Plants (WPP), and from the Logan City connection, was unaccounted for. This is comparable with the national average of 9.6\% (WSAA Facts, 2003). Unaccounted for water is made up of several components, however, background leakage and water meter inaccuracies can explain up to $85 \%$ of system water losses. Having a program in place for the renewal of meters will address the potential inaccuracies associated with apparent losses. PLM, as addressed in this paper, aims to reduce the background leakage component of system water losses by proactively identifying and repairing leaks, and by minimising the quantity of water lost through leaks by reducing water pressure.

Effective PLM on the Gold Coast involves reconfiguring the water reticulation network into a number of District Metered Areas (DMA). A DMA is a small section of the network (typically servicing 5001500 connections) that is arranged, with appropriate valving, such that it is fed (preferably) by only one water main. A flow meter would be installed on that water main, as would a flow-controlled Pressure-Reducing Valve (PRV). By using a flow-controlled PRV, the pressure in the DMA varies according to the flow (or demand) experienced in the area. It is important to note that the PRV's would be set to ensure that the pressure never drops below the Gold Coast Water minimum level of service $(220 \mathrm{kPa})$. Furthermore, in the event of high demand, such as during a fire, the PRV automatically adjusts to increase water pressure, regardless of the time of day.

In a report by Wide Bay Water (2003), it was recommended that the City’s existing water reticulation system could be divided into 155 permanent DMA’s, however, further analysis by Gold Coast Water personnel has indicated that 108 of those would be operationally and financially viable. It is proposed that the coastal strip, which incorporates a large number of high-rise developments, will not be divided into DMA's due to the operational difficulties that pressure control would cause. The DMA flow meter allows Gold Coast Water to monitor the quantity of water entering the DMA. During low flow 
periods, such as the early hours of the morning (night flows), the majority of flow being measured by the flow meter would be leakage. The location of leaks can be determined using specialized equipment, such as leak noise correlators and acoustic loggers, and then repaired. Having the water network divided into DMA's would allow Gold Coast Water to identify new leaks when they occur (by monitoring the night flows constantly and observing increases), and make it easier to find where they are occurring.

\section{PLM Field Trial - Burleigh Waters, Gold Coast, Australia}

As part of the first phase of this research investigation, a pilot study area was established to verify the actual benefits of district metering, pressure management and leakage control at a DMA level. The DMA is situated in Burleigh Waters which is part of Gold Coast Water's supply area 07. The area supplies 3,310 connections through $46.67 \mathrm{~km}$ of water mains and is supplied via a 200mm Aquamaster "S" Magflow meter and pressure reduced through a 200mm Dorot PRV. Additionally, the DMA is locked-in by two boundary valves. Water demand management at the DMA level comprised of four fundamental activities, including: establishment; flow and pressure monitoring; leakage detection; and pressure management (control).

\subsection{Establishment}

This is the physical set up of the DMA on the ground and involves closure of identified boundary valves and pressure monitoring. At this stage it was vital that a pressure zero test was conducted. This involved shutting-off the water which feeds into the DMA at the supply point, and monitoring the pressure at a point in the zone (usually the high point) to confirm the integrity of the zone. The test indicates if that DMA is "breached" (i.e. a boundary valve is open, or partly open) by observing the pressure drop at the monitoring point. If pressure does not continue to fall this indicates that the zone is being supplied by another route. All boundary valves are then checked by sounding and eventually the passing valve can be identified and fully closed (Carpenter et al., 2002). 


\subsection{Flow and Pressure Monitoring}

Flow logging allows the flow rate into a supply system to be monitored. This data was used to determine the demand of an area or if a burst had occurred. This type of incident will show up as an increase in the minimum night flow, and action can then be taken to locate the burst and have it repaired. Pressure logging determines the current pressures within the DMA and can help identify potential problems associated within a reticulation network. It is also a tool for determining whether there is scope for pressure reduction in the DMA.

\subsection{Leakage Detection}

Active Leakage Control (ALC) includes a number of methods, which can be used individually or collectively (Hunaidi, 2000): sounding; correlation survey; acoustic loggers; minimum night flow survey; and step testing. All of these methods were applied in the trial area.

\subsection{Pressure Management}

It was vital to evaluate the level of background losses in a DMA area before the introduction of pressure control. The effect of pressure control on real losses was then quantified. Pressure control was then established before conducting leak detection find-and-fix surveys (Carpenter et al., 2002; Thornton, 2004).

\subsection{Results}

The flow modulation controller was commissioned on the $01^{\text {st }}$ December 2003 with observations of immediate water savings over the first night. The controller was set to maintain 34m of pressure at the designated critical point from the 01/12/03 through to the 07/01/04. Table 1 details the total average 
water volume savings (0.24ML/day) after leakage control and flow modulation. Moreover, Fig. 1 illustrates the total reduction in average Minimum Night Flows (MNF) during the trial period.

Table 1. Total water savings in Burleigh Waters from leakage detection \& pressure control (INSERT TABLE 1 HERE)

Fig. 1. Changes in average daily night flow during the Burleigh Waters trial (INSERT FIGURE 1 HERE)

\subsection{Evaluating Service Quality}

Two service quality questionnaire surveys were disseminated pre- and post- advertising of the PLM trial results. The first questionnaire was conducted on the $16-17^{\text {th }}$ July 2004 with the population sample (n) equal to 151 in a total population (N) of approximately 6000. The results of the first part of the trial confirmed that: (1) $87 \%$ of customers were unaware that a pressure management trial was taking place in their suburb; and (2) $82 \%$ did not notice a change to their water service. This suggests the letter drop was not read completely by the resident or the survey respondent was not the same person that read the letter drop notice. Even when customers were prompted that a pressure trial was underway in their area, 70\% hadn't noticed a change in pressure. Of the respondents that did notice a change in their water service $(\mathrm{n}=18 \%$ ), the respondents revealed the following information about the cause: $57 \%$ recognised a decrease in water pressure; $15 \%$ believed there was a change in price; $1 \%$ noticed an increase in pressure; $1 \%$ noticed a change in taste; and 7\% noticed other unrelated changes.

The post-advertising survey was conducted between the 24-31 (n) of 150. Prior to this survey taking place a letter was individually posted to each resident in the trial area explaining the results of the trial. After the letter drop was complete the telephone survey commenced with the following results: $71 \%$ of respondents were now aware of the pressure trial; $65 \%$ 
of respondents did not notice a change in their water service; and of the $35 \%$ that did notice a change, $87 \%$ responded that it was low pressure.

It was evident from the trial that the pressure control technique (flow modulation) results in effective operational control of network pressures without impacting negatively on the majority of customers. Of the respondents that noticed a change in their water service, the customer survey results showed that the changes in water pressure were most evident in the garden and shower. The customers that noticed the changes to lower pressures suggested it was most noticeable between 3-8 pm. An interim analysis of the trial pressures and flow during the afternoon and evening show that demand in the afternoon is lower than the morning peak. The pressure settings for the morning peak deliver a slightly higher pressure in the morning than the afternoon and hence the customers recognising lower pressure in the afternoon. Perhaps most interestingly, the respondents that noticed the lower water pressure suggested that the overall impact on their lifestyle was low with an average response of 2.5 (1: low to 10: significant).

\subsection{Outcomes, Benefits and Impacts}

A number of monetary and non-monetary benefits resulted from the PLM strategies adopted in the Burleigh trial area. These benefits include:

- Short-term financial benefits associated with the costs of buying water from a bulk supplier, water treatment cost savings including the marginal costs of chemicals, power and sludge disposal and water reticulation costs.

- Longer-term benefits relate to whole-of-life asset costs and include a reduction in pipe failures, extended asset life and savings in the costs of repairing burst mains. There was a rapid decrease in water main and water service breaks following the implementation of pressure control in the trial area. Over the 8 months following the PRV commissioning, water main breaks reduced by approximately $80 \%$ and water service breaks by approximately $90 \%$

(Fig. 2). The infrastructure (water mains and water services) within the trial area was 
constructed between the early 1970's through to mid 1980. According to the manufacturers' specifications, at current network pressures, the water mains and services of this vintage are approximately half way through their designed asset life. The average network pressure in the Burleigh Waters trial area is at the lower end of the range at $38 \mathrm{~m}$. The remaining 16 water supply zones range between 34m and 50m. Gold Coast Water manages assets that are much older than those in the trial area. On this basis they could anticipate equivalent, if not greater savings from future trial areas.

- Indirect financial benefits also result from more efficient use of existing water supplies. In particular, reduced water losses helps to ensure that existing water supplies can meet future increases in demand. This can defer construction of new water infrastructure such as dams, treatment plants, reservoirs and water mains.

- A degree of drought security is also possible as a lower water demand means that the security of water supply can be maintained for longer periods.

- An increased knowledge of the distribution system. This enables staff to become more familiar with the system, including the location of mains and valves. This knowledge assists staff to respond more quickly to emergencies such as mains breaks and provides an early indication of any increases in water losses from leaks.

- Improved public relations can be expected as Council can inform customers of their efforts to conserve water, save money and improve service delivery by having fewer unplanned water supply failures. Field teams undertaking water audits, leak detection and maintenance work also provide visual evidence that the water system is being well maintained.

- From a total of 3,310 connections (3,877 properties) in the pilot area, only two customer complaints were received as a result of the pressure reductions in the area. These complaints related to the following: very low water pressure in a second storey bathroom due to corroded internal plumbing at a residence; and reduced operating capacity of an irrigation system at one gated community. 
PLM also offers management a range of other potential non-monetary benefits. Primarily, these relate to the environmental and social benefits of deferring or reducing the need for additional capacity in the water supply system. The construction of major dams can have substantial impacts on the environment through land clearing, changes to terrestrial and aquatic ecosystems, changes to flow regimes and water quality and disruption to existing communities. A further benefit is that loss reduction replaces system capacity at a very low cost to the Gold Coast, with very low operating costs and negligible power consumption. Consequently, it has substantial greenhouse gas benefits compared with providing additional system capacity.

Fig. 2. Observed reductions in main breaks and service breaks following pressure reduction (INSERT FIGURE 2 HERE)

\section{Future Citywide Implementation of PLM}

Preliminary investigations have indicated that 108 permanent DMA's may be financially and operationally feasible for Gold Coast City, in the existing developed areas. It is assumed that PLM would also be incorporated into new developments as the water networks are designed for those areas. Development of DMA's across the City will involve communication with customers, development of zones with appropriate valving, installation and commissioning of meters and flow-controlled PRV's, integrity testing, leakage detection and repair and pressure reduction. The pressure reduction would need to occur in stages to prevent abrupt changes to customers' water pressure. This would need to be followed by an ongoing maintenance program for the repair of any new leaks that are identified. It is estimated that the citywide implementation of DMA's would take in the order of 5 years, and if commenced in late 2005, the construction phase would be completed by 2009/10. 


\subsection{Predicted Water Savings}

Preliminary estimates indicate that the citywide implementation of PLM could potentially save 26 ML/day. It should be noted that this figure is based on the assumption that the water savings from all DMA's will be similar to that achieved in the Burleigh Waters Pilot Area. Table 2 illustrates the citywide savings if PLM was applied to 108 DMA's with an average night flow saving of $2.95 \mathrm{l} / \mathrm{s}$.

Table 2. Projected citywide water savings from PLM

(INSERT TABLE 2 HERE)

\subsection{Monetary Considerations}

The capital cost of implementing PLM citywide has been estimated at AUD\$6.5M. There will also be the ongoing costs associated with activities such as general maintenance of the system, and leakage detection and repair. As indicated previously, PLM will result in reduced water consumption and thus some reduced revenue. These reductions in revenue will be offset by savings in the cost of water treatment, reduction in pipe breaks and the associated costs to rectify these, and the deferring of headwork infrastructure.

Compared to most other reservoir zones in the city, Burleigh Waters has a relative low average pressure. On this basis we could assume that the financial savings from reduced leakage and corrective maintenance will be at least equivalent to the results of the Burleigh Waters Trial and possibly much greater. GCW has the potential to save more than AUD\$3M of its current annual corrective maintenance budget for water main and water services (Total budget is currently AUD\$5M and constitutes $25 \%$ of the total GCW maintenance budget of approximately AUD\$20M). Table 3 details the estimated annual financial savings achievable, due to reduced water main breaks, if PLM was applied across the city of the Gold Coast. 
Table 3. Corrective maintenance savings from introducing PLM

(INSERT TABLE 3 HERE)

\subsection{Qualitative Considerations}

There are a number of other advantages associated with the implementation of a widespread PLM.

These include:

- Reduced consumption of water as a direct result of finding and repairing leaks that are not immediately detectable;

- Reduced consumption of water as a result of reduced water pressure;

- Reduced consumption of water as a result of reduced property service and water main breaks;

- Improved customer service due to reduced property service and water main breaks;

- Longer asset life; and

- Reduced costs associated with maintenance and renewal of water mains and property services.

Adversely, there are some potential negative impacts associated with the implementation of a widespread PLM program. These include:

- The potential for some customers to experience failure of internal plumbing, hot water services or automatic sprinkler systems that were designed for, or only operated due to, the previously experienced high water pressures; and

- Water quality problems associated with having more 'dead-ends' in the reticulation network. However, this can generally be managed with careful design of DMA's and regular flushing of dead-end mains. 


\subsection{Water Supply Options Comparative Analysis}

The main advantage of PLM is that, when compared with its alternatives, it offers the least cost alternative to other water supply options. Table 4 illustrates the difference in cost per mega litre per day between the various water supply options, including, raising the Hinze Dam, building a pipeline to Wivenhoe Dam, and Desalination projects.

Table 4. Comparison of available water supply options (Gold Coast Water, 2003) (INSERT TABLE 4 HERE)

\subsection{Summary}

PLM presents a good opportunity to achieve significant water savings across Gold Coast City. The pilot trial in Burleigh Waters achieved excellent results, with a significant reduction in leakage and consumption of $2.95 \mathrm{~L} / \mathrm{s}$ across the area, and reduced property service and water main breaks (80\% and $90 \%$ respectively). On that basis, and given the pressures throughout the remainder of the city are higher and assets significantly older, GCW have an opportunity to capitalise on obvious operational improvements to the water reticulation network. Following the least cost planning rule, PLM should constitute one of the first infrastructure projects implemented by GCW to improve its' network efficiency and passively reduce demand for the water supply.

\section{Directions for Future Research}

PLM is much more than an operational technique to reduce leaks and water main breaks. It can also impact on every aspect of the total water cycle. The most significant impact of PLM on the total water cycle appears to be in reduced energy consumption (Colombo and Karney, 2005) across the network and the deferral of future capital expenditure. However, there are also savings in other less tangible areas, including: deferral of energy supply infrastructure as a result of the cumulative impact of all 
water companies adopting pressure management; the environmental cost of reduced greenhouse emissions; the future costs of carbon trading for water companies; and the cost to customers of improved security of supply and fewer interruptions (Starkyl and Brunner, 2004).

While PLM was identified as the least cost approach to water supply planning, the equation used to calculate the least cost did not account for less tangible items described above. Future research should attempt to develop a comprehensive list of quantifiable triple-bottom-line PLM factors which impact on the total water cycle. This will undoubtedly provide further support for PLM and cement its' place at the least cost end of the water supply infrastructure ladder.

To provide further support for recently formulated PLM policy recommendations, researchers and/or practitioners should develop a decision support tool for water supply managers, that provides a comprehensive analysis of the potential savings (i.e. water, infrastructure, energy, CO2, infrastructure deferral, etc.). Further to supporting policy, a decision support tool would assist water supply planners in analyzing PLM as a valid diversification option. Of particular importance is the inclusion of the triple-bottom-line indicators to measure the potential benefits of PLM.

Presuming that PLM acts as a surrogate measure of sustainability, the opportunity exists for water companies to demonstrate their sustainable performance by reporting on PLM. The same decision support tool, that is used to measure the potential benefits of implementing PLM, could also be used to benchmark and measure its’ performance.

As populations continue to grow and rainfall patterns become less reliable, competition for water resources will increase and be reflected by an upward pressure on access to water. The obvious path will be to manage access through reflective pricing. As the pricing elasticity intersection narrows, consumers will begin to demand transparency in accounting the cost of their water supply. A combined decision support and benchmarking tool will provide this transparency and assist government water service providers in moving toward sustainable operational practice. 


\section{References}

Australia Bureau of Statistics (2004). Population Projections, Australia, Cat. No. 3222.0.

Babovic, V., Drecourt, J., Keijzer, M., and Hansen, P. F. (2002). “A data mining approach to modelling of water supply assets.” Urban Water, 4(2). 401-414.

Buchberger, S.G., and Nadimpalli, G. (2004). "Leak detection in water distribution systems by statistical analysis of flow readings.” Journal of Water Resources Planning and Management, 130(4), 321-329.

Burrows R., Crowder G.S., and Zhang J. (2000). "Utilisation of network modelling in the operational management of water distribution systems.” Urban Water, 2, 83-95.

Carpenter, T., Lambert, A., and McKenzie, R. (2002). “Applying the IWA approach to water loss performance indicators in Australia.” Proc., Enviro. 2002 \& IWA $3^{\text {rd }}$ World Water Congress, Melbourne, Australia, p. 405.

Colombo, A.F., and Karney, B.W. (2005). "Impacts of leaks on energy consumption in pumped systems with storage.” Journal of Water Resources Planning and Management, 131(2), 146-155.

Crimp, S. (2004). "Presentation to the Minister of the Department of Natural Resources and Mines.” Queensland Drought Security Taskforce, Parliament House, October 2004.

Cullen, R. (2004). "Pressure vs. consumption relationships in irrigation systems.” Research Thesis. University of Queensland, Australia. 
Dube, E., van der Zaag, P. (2003). “Analysing water use patterns for demand management: the case of the city of Masvingo, Zimbabwe.” Physics and Chemistry of the Earth, 28(5); 805-815.

Dan, K., and Beaton, R. (2004). “Applying an appropriate leakage indicator.” WSAA Journal, 2, November, Water Services Association of Australia.

deMonsabert, S., and Liner, B.L. (1998). "Integrated energy and water conservation modelling." Journal of Energy Engineering, 124(1), 1-19.

Gold Coast Water (2004). Gold Coast Waterfuture Discussion Starter. Gold Coast City Council.

Gold Coast Water (2003). Gold Coast Water - Water Balance Discussion Paper. Gold Coast City Council.

Haddad M., and Lindner K. (2001). "Sustainable water demand management versus developing new and additional water in the Middle East: a critical review.” Water Policy, 3(5), 143-163.

Hunaidi, O. (2000). "Detecting leaks in water distribution pipes.” National Research Council of Canada, Construction Technology Update No.40. Institute for Research in Construction. Ottawa.

Jankovic-Nisic, B., Maksimovic, C., Butler, D., and Graham, N.J.D. (2004). "Use of flow-meters for managing water supply networks.” Journal of Water Resources Planning and Management, 130(2), $171-179$.

Kolokytha, E.G., Mylopoulos, Y.A., and Mentes, A.K. (2002). "Evaluating demand management aspects of urban water policy - A field survey in the city of Thessaloniki, Greece.” Urban Water, 4, 391-400. 
Makropoulos, C.K., Butler, D., and Maksimovic, C. (2003). "Fuzzy logic spatial decision support system for urban water management.” Journal of Water Resources Planning and Management, 129(1), 69-77.

Marques, R.C., and Monteiro, A.J., (2002). “Application of performance indicators to control losses results from the Portuguese water sector." Proc. of the Enviro. 2002 \& IWA $3^{\text {rd }}$ World Water Congress, Melbourne, Australia, p. 235.

Mulwafu, W., Chipeta, C., Chavula, G., Ferguson, A., Nkhoma, B.G., and Chilima, G. (2003). "Water demand management in Malawi: problems and prospects for its promotion.” Physics and Chemistry of the Earth, 28(7), 787-796.

Misiunas, D. Vítkovský, J. Olsson, G. Simpson, A. and Lambert, M. (2005) “Pipeline break detection using pressure transient monitoring.” Journal of Water Resources Planning. and Management, 131(4), 316-325.

Mwendera, E.J., Hazelton, D., Nkhuwa, D., Robinson, P., Tjijenda, K., and Chavula, G. (2003). "Overcoming constraints to the implementation of water demand management in southern Africa." Physics and Chemistry of the Earth, 28(7), 761-778.

Pilipovic, Z., and Taylor, R. (2002). "Pressure Management in Waitakare City - A case study.” Proc. of the Enviro. 2002 \& IWA $3^{\text {rd }}$ World Water Congress, Melbourne, Australia, p.260.

Poulakis, K., Valougeorgis, D., and Papadimitriou, C. (2003). "Leakage detection in water pipe networks using a Bayesian probabilistic framework”. Probabilistic Engineering Mechanics, 18(3), 315-327. 
Rockstrom J., (2003). "Resilience building and water demand management for drought mitigation.” Physics and Chemistry of the Earth, 28(5), 869-877.

Sokile, C.S., Kashaigili, J.J., and Kadigi, R.M.J. (2003). "Towards an integrated water resource management in Tanzania: the role of appropriate institutional framework in Rufiji Basin.” Physics and Chemistry of the Earth, 28 (3), 1015-1023.

Starkl M., and Brunner N., (2004). "Feasibility versus sustainability in urban water management." Journal of Environmental Management, 71(1), 245-260.

Thornton, J. (2002). “Managing leakage by managing pressure - a practical approach.” Water21, IWA Water Loss Task Force.

Wide Bay Water Corporation (2003). "Water loss evaluation and development of a leakage control district metering and pressure management strategy.” Wide Bay Water Corporation - Report for Gold Coast Water, June 2003, Hervey Bay, Australia.

WSAA. (2003). “The Australian urban water industry - WSAAfacts 2003.” Water Services Association of Australia, ISSN 1328-2751.

\section{Acknowledgements}

The authors would like to acknowledge the staff and director of Gold Coast Water, Mr. Shaun Cox, Chair or the Water Sustainability Committee, Cr. Daphne MacDonald and the Mayor of Gold Coast City, Cr. Ron Clarke for providing the necessary trial study data to make this research study possible. 
Table 1. Total water savings in Burleigh Waters from leakage detection \& pressure control

\begin{tabular}{lcc}
\hline PLM Project Phase & Average MNF & Difference in MNF \\
\hline Average MNF Pre - LD* \& PR** (adjusted) & $6.20 \mathrm{l} / \mathrm{sec}$ & $\mathrm{N} / \mathrm{A}$ \\
Average MNF Post - LD* \& PR** & $4.13 \mathrm{l} / \mathrm{sec}$ & $2.33 \mathrm{l} / \mathrm{sec}$ \\
Average MNF Post - LD* \& PR** and Flow Modulation & $3.25 \mathrm{l} / \mathrm{sec}$ & $0.88 \mathrm{l} / \mathrm{sec}$ \\
\hline & & $2.95 \mathrm{l} / \mathrm{sec}$ \\
Average total saving & & or $0.24 \mathrm{ML} / \mathrm{day}$ \\
& & or $89.15 \mathrm{ML} / \mathrm{year}$ \\
\hline *LD - Leakage Detection & &
\end{tabular}

**PR - Pressure Reduction

Table 2. Projected citywide water savings from PLM

\begin{tabular}{cccc}
\hline $\begin{array}{c}\text { Potential leakage } \\
\text { savings } \\
\text { (l/sec/DMA) }\end{array}$ & $\begin{array}{c}\text { Leakage savings over 108 } \\
\text { DMA's } \\
(\mathrm{l} / \mathrm{sec})\end{array}$ & $\begin{array}{c}\text { Total annual savings } \\
\text { (ML/day) }\end{array}$ & $\begin{array}{c}\text { Total annual savings } \\
\text { (ML/year) }\end{array}$ \\
\hline 0.50 & 54.00 & 4.47 & 1631.98 \\
1.00 & 108.00 & 8.94 & 3263.97 \\
1.50 & 162.00 & 13.41 & 4895.96 \\
2.00 & 216.00 & 17.88 & 6527.95 \\
2.50 & 270.00 & 22.35 & 8159.94 \\
2.95 & 318.60 & 26.38 & 9628.72 \\
3.00 & 324.00 & 26.82 & 9791.92 \\
\hline
\end{tabular}

Table 3. Corrective maintenance savings from introducing PLM

\begin{tabular}{lccc}
\hline & $\begin{array}{c}\text { Annual corrective maintenance } \\
\text { budget (AUD\$) }\end{array}$ & $\begin{array}{c}\text { Assumed \% reduction } \\
\text { in breaks }\end{array}$ & $\begin{array}{c}\text { Total AUD\$ } \\
\text { saving* }\end{array}$ \\
\hline Water main breaks & $\$ 2,600,000$ & $80 \%$ & $\$ 1,664,000$ \\
Water service breaks & $\$ 2,400,000$ & $90 \%$ & $\$ 1,728,000$ \\
\hline \multicolumn{2}{l}{ Total annual saving on corrective maintenance } & & $\$ 3,392,000$ \\
\hline * Corrected for \% of city under pressure control (approx. 80\%) & &
\end{tabular}

Table 4. Comparison of available water supply options (Gold Coast Water, 2003)

\begin{tabular}{lccc}
\hline Water source & $\begin{array}{c}\text { Total cost } \\
\text { AUD\$ }\end{array}$ & $\begin{array}{c}\text { Total daily water production } \\
\text { or saving (ML/day) }\end{array}$ & $\begin{array}{c}\text { Cost/ML/day } \\
\text { AUD\$ }\end{array}$ \\
\hline Wivenhoe Pipeline * & $\$ 81,000,000$ & 85.00 & $\$ 952,941$ \\
Hinze 3 * & $\$ 80,000,000$ & 27.00 & $\$ 2,962,962$ \\
Leakage and Pressure Control & $\$ 6,500,000$ & 26.38 & $\$ 246,398$ \\
Desalination * & N/A & N/A & $\$ 3,000,000$ \\
Total Rebate Scheme (to date) \# & $\$ 521,220$ & 0.36 & $\$ 1,438,645$ \\
Shower Rose Rebate (\$10/unit) ^ & $\$ 7,770$ & 0.038 & $\$ 202,776$ \\
\hline * supply side option figures include capital costs only (Gold Coast Water, 2003) \\
\# excludes results for \$200 washing machine rebate. Accurate to Feb 29, 2004. \\
$\wedge$ assumes savings of 18kl/unit/ann. Accurate to Feb 29, 2004.
\end{tabular}




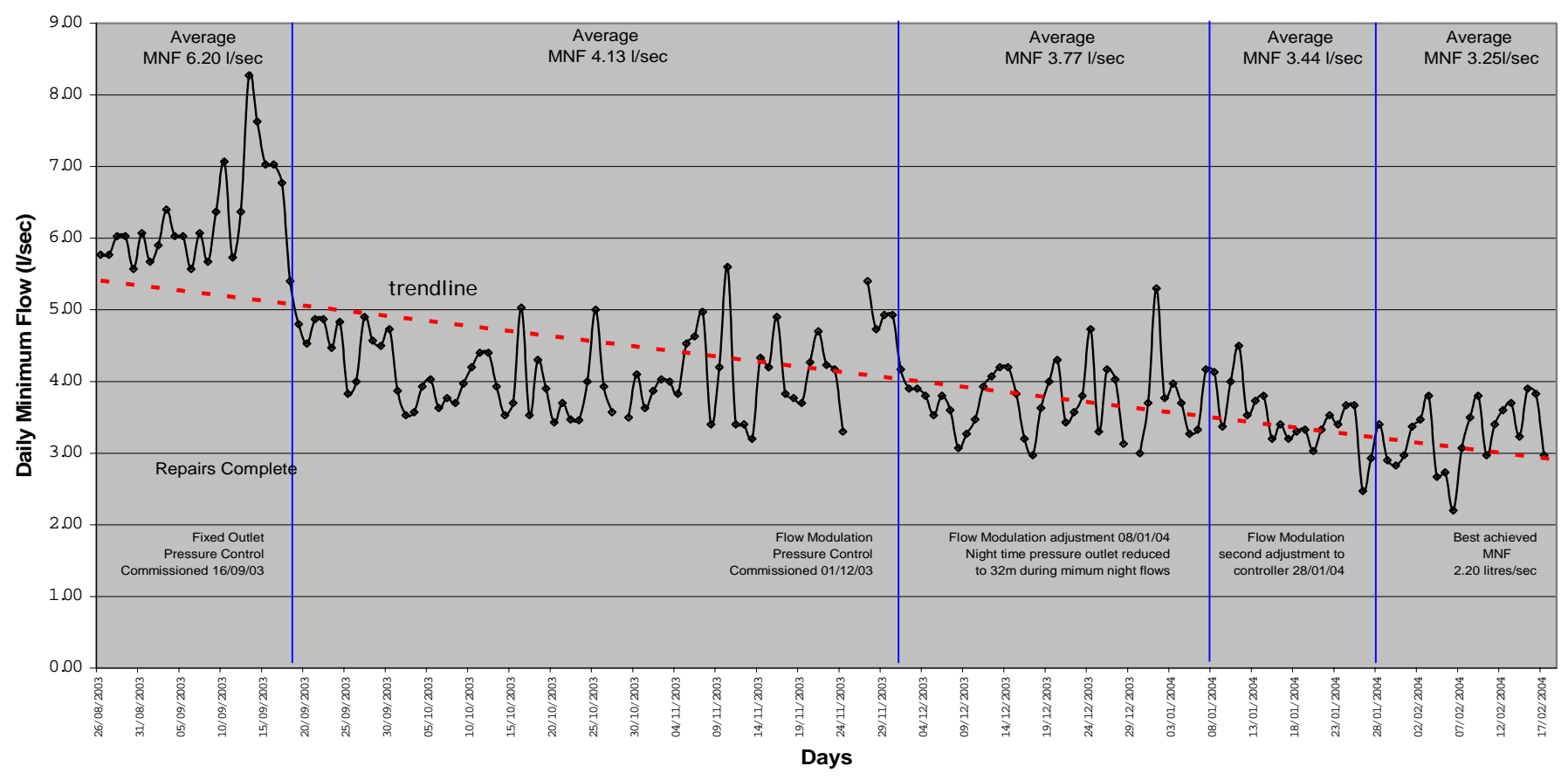

Fig. 1. Changes in average daily night flow during the Burleigh Waters trial

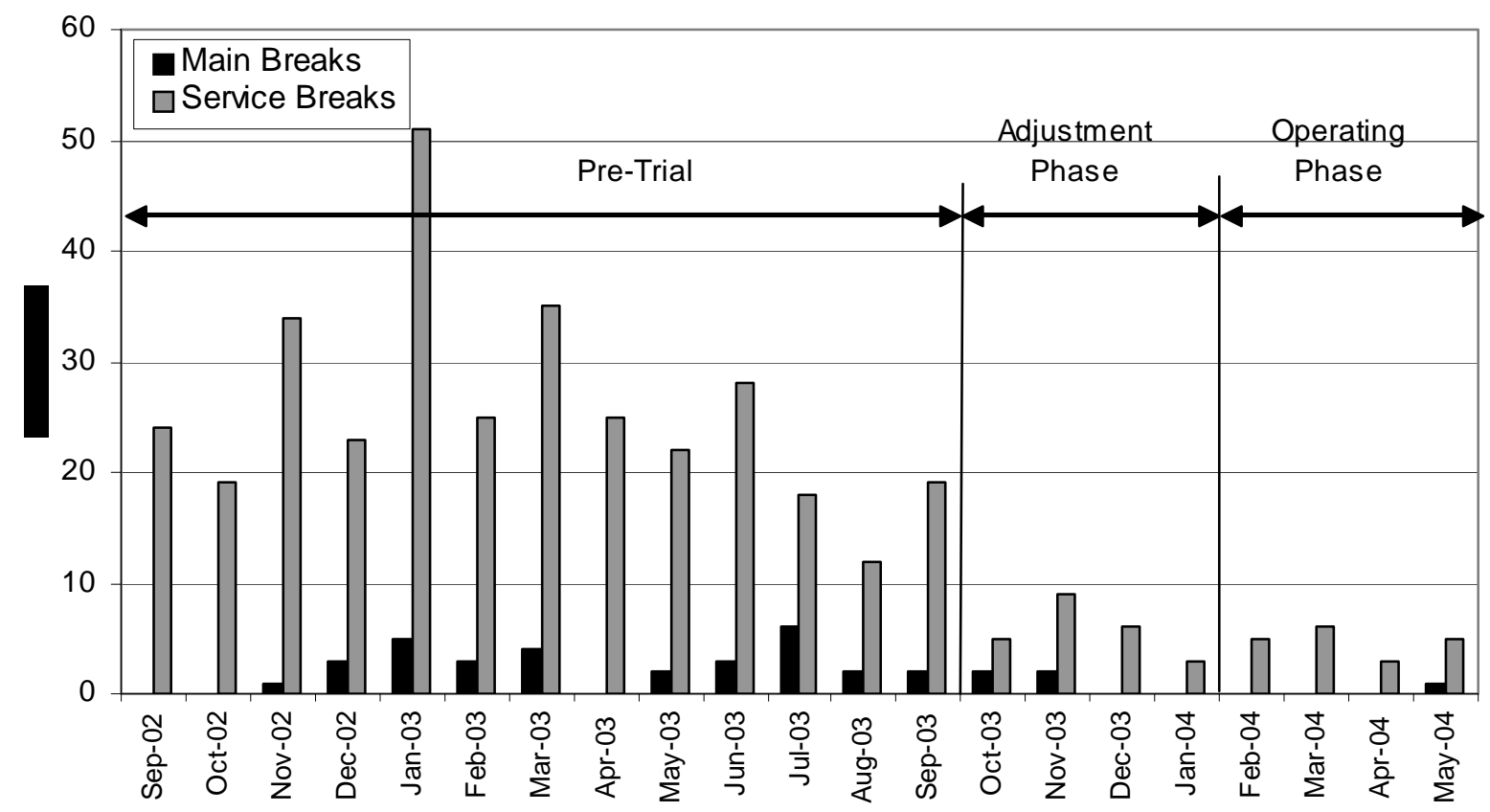

Fig. 2. Observed reductions in main breaks and service breaks following pressure reduction 